\title{
Formulation and in vitro Characterization of Time Release Tablets of Propranolol Hydrochloride
}

\author{
S. GIRI AND S. MOHAPATRA* \\ Department of Pharmaceutics, School of Pharmaceutical Sciences, Siksha ' $O$ ' Anusandhan (Deemed to be University), \\ Bhubaneswar, Odisha-751 003, India
}

Giri and Mohapatra: Evaluation of TR tablet of Propranolol Hydrochloride

\begin{abstract}
The objective of this investigation was to prepare and evaluate propranolol hydrochloride time release tablets using press coating technique. The time release tablet consisted of two layers, a core tablet containing the active ingredient and an outer cell coating. The core tablet was prepared with the active ingredient using conventional method. Press coated optimized tablet was formulated using different ratios of ethyl cellulose and hydroxypropyl methylcellulose K4M. The coated tablets were evaluated by estimating the physical attributes, drug content, X-ray powder diffraction, Fourier-transform infrared spectroscopy and in vitro drug release profile. Based on the evaluation parameters formulation F10 showed a 6 h release lag time. The release pattern of $\mathrm{F} 10$ formulation fulfilled the circadian variation matching the chronotherapeutic objective of hypertension.
\end{abstract}

Key words: Propranolol hydrochloride, press coated, chronotherapy, time release

Time release (TR) tablets are gaining importance as this technology delivers medicine at a specific moment according to a disease's pathophysiological requirements, leading to enhanced therapeutic effectiveness and patient compliance. These systems are useful for drugs with chronopharmacological behavior (where night dosage is required), first-pass effect, and explicit ingestion site in the gastrointestinal $\operatorname{tract}^{[1]}$. By regulating the dosing routine of drug administration as indicated by physiological needs, chronotherapy has now been widely linked in clinical treatment. Different diseases such as asthma, hypertension and arthritis show circadian variety that demand time planned drug release for successful drug activity ${ }^{[2]}$. Following the effects of a few epidemiological investigations, the $24 \mathrm{~h}$ cycle shows increased danger of various pathologies. The risk factor for patients suffering with cardiovascular diseases are more in early morning as the blood pressure rises in a significant manner just before awakening. So for treatment of hypertension delivery of drug is required early in the morning, when blood pressure is at its peak after a suitable lag period covering midnight hours, when blood pressure declines. To fulfill this prerequisite, new innovation based on TR was created ${ }^{[3-6]}$.

*Address for correspondence E-mail: sujatamohapatra@soa.ac.in

March-April 2020
TR drug delivery can be accomplished by formulating the tablet either in form of coated matrix tablets or coating the directly compressed core tablets by film coating or press coating ${ }^{[7-11]}$. Comparing the above techniques press coated tablets provide solvent free coating method that also requires no unique tool, and pressure shaped coating provides greater strength as compared to film coating ${ }^{[12-14]}$.

This sim of this study was to develop press coated TR tablet of propranolol hydrochloride $(\mathrm{PNH})$. $\mathrm{PNH}$ is a $\beta$ blocker that blocks the $\beta 1$ receptor in the kidney and reduces the discharge of renin. Renin angiotensin system impacts decrease and blood pressure decrease ${ }^{[15]}$. A well-known water insoluble polymer, ethyl cellulose (EC) serves to modulate drug release as a controlling membrane. Hydroxypropyl methylcellulose (HPMC) is a widely used swellable polymer in the pharmaceutical industry that acts as an extended release agent ${ }^{[16,17]}$.

This is an open access article distributed under the terms of the Creative Commons Attribution-NonCommercial-ShareAlike 3.0 License, which allows others to remix, tweak, and build upon the work non-commercially, as long as the author is credited and the new creations are licensed under the identical terms

Accepted 08 January 2020

Revised 09 December 2019

Received 28 September 2019

Indian J Pharm Sci 2020;82(2):216-221 
The purpose of this examination was to establish a planned and controlled TR tablet that would release the drug quickly before risk time in the early morning and continue to release drug latter to treat hypertension. The TR tablet was meant to have a $6 \mathrm{~h}$ initial lag time and latter sustained release in view of this idea ${ }^{[18,19]}$.

\section{MATERIAL AND METHODS}

The materials used were, propranolol hydrochloride (PNH, Macleods Pharmaceuticals, Sikkim), microcrystalline cellulose (MCC, Hiranya Cellulose Products, Hyderabad), lactose (Benzer Multi Tech India Private Limited, Pune), magnesium stearate (Eklingjee Polymers Private Limited, Delhi), talc (Goyal Enterprises, Jaipur), ethyl cellulose (EC, Perry Impex, Maharashtra), hydroxypropyl methylcellulose K4M (HPMC K4M, Paarichem Resources LLP, Mumbai), barium sulphate X-ray Grade (Mahavir Chemical Industries, Delhi). All chemicals used were of analytical grade. Ethanol and hydrochloric acid was of HPLC grade and were purchased from Nanda Enterprises Mumbai, India. The equipment used used were, electronic balance (Wensar), hydraulic compression machine (Technosearch), UV/Vis spectrophotometer (Jasco V-630), hardness tester (Dr. Schleuinger Pharmaton), disintegration apparatus (Technolab), dissolution apparatus (Electrolab TDT06L), FT-IR (Jasco 4600) and XRD (Miniflex 600).

\section{Preparation of PNH core tablet:}

The core tablet of PNH was formulated using direct compression technique. Precisely weighed PNH and excipients other than glidant and lubricant were passed through 60 mesh sieve and were mixed in a petri dish. Talc and magnesium stearate lubricated the prepared mix for a further $5 \mathrm{~min}$ and heated for the next $30 \mathrm{~min}$ at $40^{\circ}$ in a hot air oven. Thereafter the resulting blend was compressed directly using $8 \mathrm{~mm}$ round level punches in a hydraulic press tableting machine. PNH was $40 \mathrm{mg}$ per core tablet and the final weight was adjusted to $150 \mathrm{mg}$ for each core tablet (Table 1).

\section{Preparation of press coated tablet:}

Table 2 showed that the core PNH tablets were coated with coat constituents in different ratios of EC and HPMC K4M. Here, half of the coat materials were placed in a die cavity and then the core PNH tablet was placed in the centre of the die cavity and then loaded with the other part of the coating material. For compression $13 \mathrm{~mm}$ round flat and simple punches were used.

\section{Physicochemical characterization and drug content uniformity of PNH core tablet:}

According to the Indian Pharmacopoeia (IP 2018), physicochemical parameters such as hardness, weight variation and friability were evaluated. The PNH press coated tablets were also subjected to similar evaluation for physicochemical parameters. For drug content estimation, 10 tablets were taken and triturated and precisely $100 \mathrm{mg}$ of the powder was weighed and placed in a $100 \mathrm{ml}$ volumetric flask. Then $75 \mathrm{ml}$ of $95 \%$ ethanol was added mixed and filtered. Five millilitres of the filtrate was diluted with $50 \mathrm{ml}$ of ethanol and the PNH concentration was estimated on a UV spectrophotometer at $289 \mathrm{~nm}$ utilizing proper blank solution. The quantity of PNH was determined from the calibration curve.

\section{In vitro disintegration time and dissolution of $\mathrm{PNH}$ core tablet:}

In vitro disintegration time was determined by taking 6 tablets from every batch and were placed in a digital tablet disintegration apparatus. In vitro disintegration was determined at $37 \pm 2^{\circ}$ in $900 \mathrm{ml}$ of $\mathrm{pH} 6.8$ phosphate buffer. The in vitro dissolution studies were done in $\mathrm{pH} 6.8$ phosphate buffer $(900 \mathrm{ml})$ at $37 \pm 5^{\circ}$ employing the USP dissolution apparatus type II. The rotation speed was fixed at $50 \mathrm{rpm}$. Aliquots of dissolution medium were taken out at predetermine time intervals and content of PNH was determined using the UV spectrophotometer at $289 \mathrm{~nm}$. The dissolution studies were performed in triplicate.

\section{FTIR and XRD analysis of press coated tablets:}

The compatibility between PNH and formulation excipients was evaluated using FTIR employing the $\mathrm{KBr}$ pellet method. The spectra obtained were compared and interpreted for useful functional group bands. X-ray diffraction spectrum of $\mathrm{PNH}$, the polymer and the optimized formulation was recorded with X-ray diffractometer with ray-flex technology using $\mathrm{Ni}$ -

\begin{tabular}{lc} 
TABLE 1: FORMULATION OF PNH CORE TABLET \\
\hline Materials & Amount (mg) \\
\hline Drug & 40 \\
MCC & 60 \\
Lactose & 47.75 \\
Magnesium stearate & 0.75 \\
Talc & 1.5 \\
Total & 150 \\
\hline
\end{tabular}

PNH is propranolol hydrochloride, MCC is microcrystalline cellulose, SE is the standard error of the mean, SD is standard deviation for $n$ $=3$ observations 
TABLE 2: FORMULATION OF PRESS COATED TABLET

\begin{tabular}{lcc}
\hline Formulation & EC $(\mathbf{m g})$ & HPMC K4M (mg) \\
\hline F1 & 300 & $\cdots$ \\
F2 & 150 & 300 \\
F3 & 260 & 150 \\
F4 & $\cdots$ & 260 \\
F5 & 130 & 130 \\
F6 & 195 & 65 \\
F7 & 240 & $\cdots$ \\
F8 & $-\cdots-\cdots$ \\
F9 & 120 & 240 \\
F10 & 180 & 120 \\
F11 & & 60
\end{tabular}

TABLE 3: PHYSICO CHEMICAL PARAMETER OF PNH CORE TABLET

\begin{tabular}{lccccc}
\hline Formulation & $\begin{array}{c}\text { Tablet weight }(\mathrm{mg}, \\
\mathrm{n}=3)\end{array}$ & $\begin{array}{c}\text { Disintegration time } \\
(\mathrm{s}, \mathrm{n}=6)\end{array}$ & $\begin{array}{c}\text { Hardness }(\mathrm{N}, \\
\mathrm{n}=3)\end{array}$ & $\begin{array}{c}\text { Friability }(\%, \\
\mathrm{n}=10)\end{array}$ & $\begin{array}{c}\text { Drug Content }(\%, \\
\mathrm{n}=10)\end{array}$ \\
\hline PNH CORE TABLET & $148 \pm 0.83$ & $100 \pm 2.34$ & $2.1 \pm 0.04$ & $0.353 \pm 0.013$ & $98 \pm 0.44$ \\
\hline
\end{tabular}

$\mathrm{N}$ stands for Newton and sec stands for second

TABLE 4: PHYSICOCHEMICAL PARAMETERS OF PRESS COATED TABLET

\begin{tabular}{lccc}
\hline Formulation & $\begin{array}{c}\text { Tablet Weight } \\
(\mathrm{mg}, \mathrm{n}=3)\end{array}$ & $\begin{array}{c}\text { Hardness } \\
(\mathrm{N}, \mathrm{n}=3)\end{array}$ & $\begin{array}{c}\text { Friability } \\
(\%, \mathrm{n}=10)\end{array}$ \\
\hline F1 & $297 \pm 1.15$ & $5.7 \pm 0.4$ & $0.226 \pm 0.023$ \\
F2 & $298 \pm 1.13$ & $6.1 \pm 0.3$ & $0.246 \pm 0.013$ \\
F3 & $298 \pm 1.11$ & $5.3 \pm 0.4$ & $0.248 \pm 0.013$ \\
F4 & $257 \pm 0.5$ & $4.0 \pm 0.71$ & $0.225 \pm 0.010$ \\
F5 & $259 \pm 0.52$ & $5.7 \pm 0.69$ & $0.249 \pm 0.012$ \\
F6 & $258 \pm 0.48$ & $4.7 \pm 0.7$ & $0.248 \pm 0.013$ \\
F7 & $258 \pm 0.51$ & $4.5 \pm 0.7$ & $0.276 \pm 0.031$ \\
F8 & $238 \pm 0.63$ & $4.1 \pm 0.34$ & $0.223 \pm 0.022$ \\
F9 & $238 \pm 0.61$ & $4.5 \pm 0.30$ & $0.247 \pm 0.014$ \\
F10 & $239 \pm 0.60$ & $4.9 \pm 0.37$ & $0.245 \pm 0.012$ \\
F11 & $239 \pm 0.63$ & $4.7 \pm 0.35$ & $0.249 \pm 0.012$ \\
\hline
\end{tabular}

filtered, $\mathrm{Cu}-\mathrm{K}-\alpha$-radiation, $40 \mathrm{kV}$ and $30 \mathrm{~mA}$ current at a scan rate of $10 \% \mathrm{~min}$. The instrument worked in constant output mode over a $5-50^{\circ}, 2 \theta$ scope at a $10.3 \mathrm{sec}$ phase moment. The comparative power I/I0 and the interplanar distance compared to the $2 \theta$ qualities were accounted and examined.

\section{In vitro dissolution study of press coated tablet:}

In vitro dissolution studies were performed in a USP dissolution type-II (paddle type) apparatus, in $500 \mathrm{ml}$ medium at $37 \pm 5^{\circ}$ at a rotation speed of $50 \mathrm{rpm}$. In light of lag time the press coated tablets was tested at $0.1 \mathrm{~N}$ $\mathrm{HCl}$ at first for $2 \mathrm{~h}$ and after which the dissolution was studied in $\mathrm{pH}$ 6.8, which is similar to intestinal media. At predetermined time intervals, samples were withdrawn and replenished by an equivalent volume of fresh dissolution medium to maintain consistent volume. The withdrawn samples were filtered, diluted and analysed on a UV spectrophotometer at $289 \mathrm{~nm}^{[20,21]}$.

\section{RESULT AND DISCUSSION}

The measured core tablet hardness was found to be $2.1 \pm 0.04 \mathrm{~N}$ for all formulations. This ensured that all batches possessed good handling characteristics. As the percent weight variation was within the limits of pharmacopoeia, the entire formulated core tablet passed the test. It was found that all tablet weights were uniform with low standard deviation. Tablet thickness was found to be $8 \mathrm{~mm}$. The percent friability was less than one for all formulations, indicating that the batches were within the prescribed limits. The results of friability indicated that the tablets possessed good mechanical strength. It was found that the core tablets disintegrated rapidly within $100 \mathrm{sec}$. The content of PNH was found to be very high in all the cases. The assay value was $98 \%$ of the labeled amount indicating uniformity of drug content (Table 3). The results obtained for post compression parameters are summarized in the Table 4. The coated tablet passed these tests as the data were within the pharmacopoeial limits. FTIR spectra revealed that there was minimal drug carrier interaction. The amine group showed a broadband at $3373 \mathrm{~cm}^{-1}$ due to probable interaction of intramolecular hydrogen bonds. In addition to that no other functional group of PNH interfered with the formulation excipients (fig. 1). PNH XRD pattern showed intense, sharp peaks showing its crystalline nature. In the case of the formulation, numerous distinct peaks indicated that the crystallinity was reduced in comparison to the pure drug (fig. 2).

From the dissolution study it was observed that the core tablet showed rapid drug release, which was $99 \%$ within 30 min (fig. 3) following a conventional release pattern. 


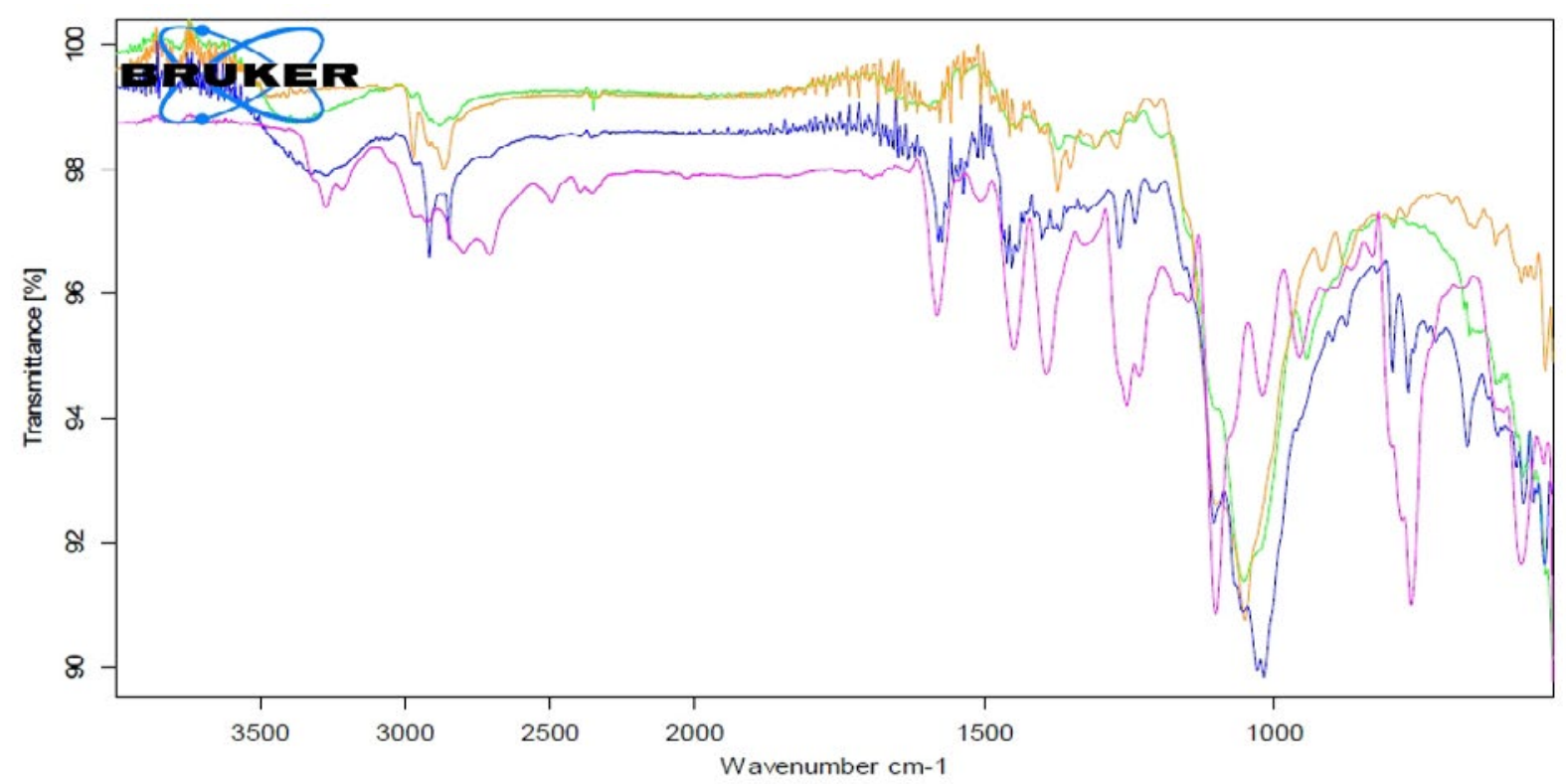

Fig. 1: FTIR Spectra of PNH, EC, HPMC K4M and formulation

Propranolol hydrochloride (PNH, ----), formulation (-----), EC (----) and HPMC K4M (----)

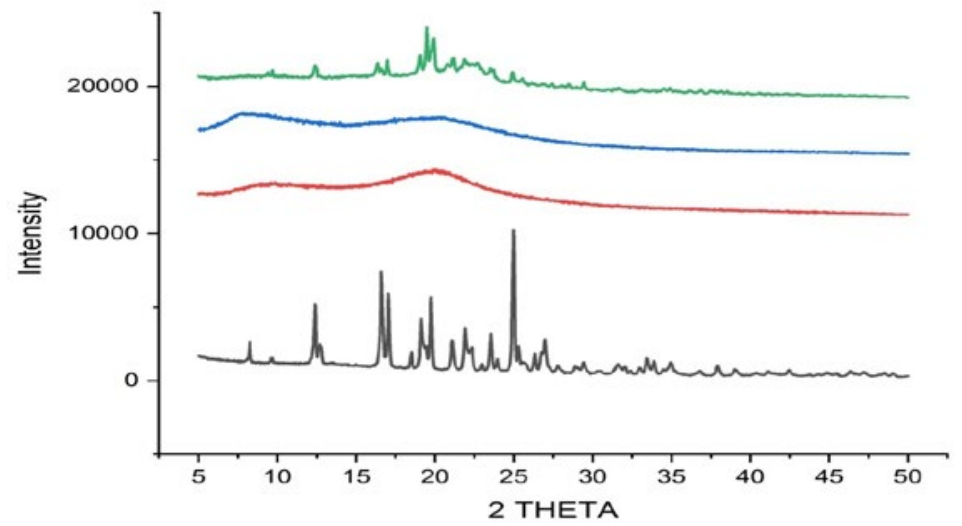

Fig. 2: XRD of PNH, EC, HPMC K4M, Formulation,

Propranolol hydrochloride (PNH -$)$, EC (-), HPMC K4M (-) and formulation (-)

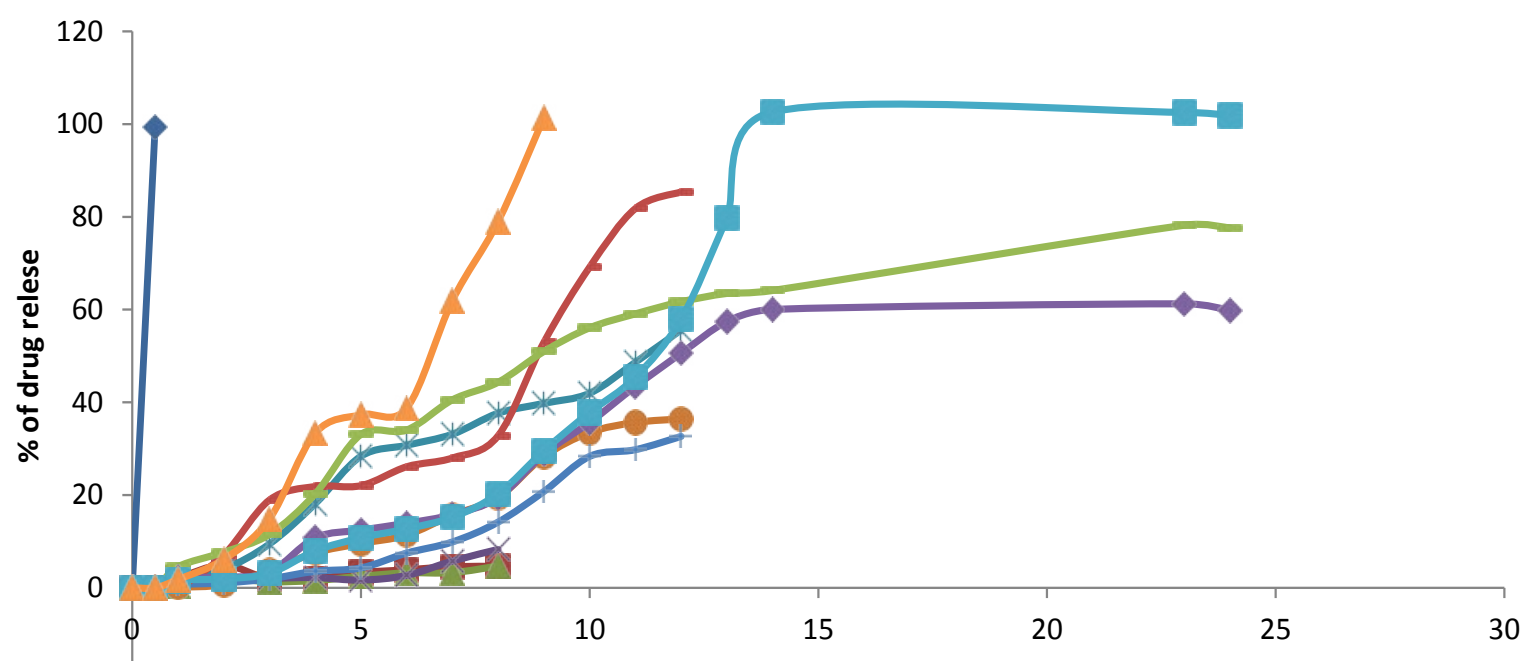

$-20$

time (h)

Fig. 3: In vitro release profile of $\mathrm{PNH}$ and formulations,

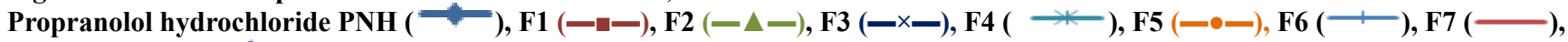
F8 ( - , F9 (- - , F10 (- - - ) and F11 (- $\left.-{ }_{-}\right)$ 


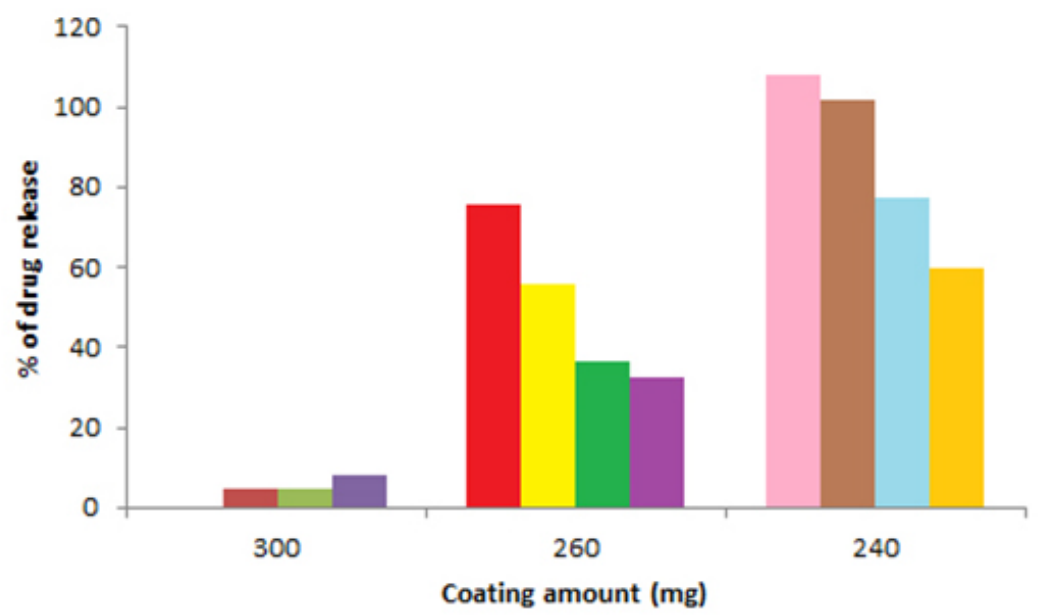

Fig. 4: Effect of coating thickness on drug release

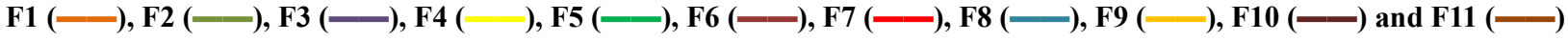

For formulating the TR tablet of $\mathrm{PNH}$, a predetermined lag time followed by release at a programmed manner, the outer press coat material should resist the GI fluid before it disintegrated or ruptured in the intestine. Therefore, maintenance of lag time for the press coated tablet was a key parameter. Through optimization of the proportions of EC and HPMC K4M in the press coat, it was programmed to achieve a lag period of $6 \mathrm{~h}$ initially followed by sustained drug release. It is likely that lag time for drug release was controlled by a combination of the thickness and the viscous gel forming layer of HPMC and impermeable layer of EC. The optimized formulation F10 fulfilled all expectations maintaining a lag time of $6 \mathrm{~h}$ and followed by releasing PNH in a sustained manner. The thickness of the coat material is a major parameter for sustaining drug release, working as a barrier. The release pattern could be programmed by changing the coat thickness (fig. 4).

From the results of this investigation, it could be concluded that the prepared press coated TR tablets of $\mathrm{PNH}$ appears to be suitable for administration at bed time to release the drug in the early morning when chances of hypertension are more likely there by fulfilling the therapeutic requirement of the disease.

\section{ACKNOWLEDGEMENTS}

The authors are grateful to the School of Pharmaceutical Sciences, Siksha 'O' Anusandhan (Deemed to be University), Bhubaneswar for providing the research facilities.

\section{REFERENCES}

1. Rane A, Babulal A, Gattani S, Kadam V, Tekade A. Formulation and Evaluation of Press Coated Tablets for Pulsatile Drug Delivery Using Hydrophilic and Hydrophobic Polymers. Chem Pharm Bull 2009;57(11):1213-17.
2. Jagdale S, Pawar C. Application of Design of Experiment for Polyox and Xanthan gum Coated Floating Pulsatile Delivery of Sumatriptan Succinate in Migraine Treatment. Bio Med Res Int 2014;18(17):101-11.

3. Sumathi P, Kaza R. Design and Development of Pulsatile Drug Delivery of Nateglinide Using Pulsincap Technology. Int J Innov Pharm Sci Res 2014;5(3):425-30.

4. Davoodi P, Lee L, Xu Q, Sunil V, Sun Y, Soh S. Drug delivery systems for programmed and on-demand release. Adv Drug Deliv Rev 2018;132:104-38.

5. Ghimire M, McInnes F, Watson D, Mullen A, Stevens H. In vitro/In vivo Correlation of Pulsatile Drug Release from PressCoated Tablet Formulations: A Pharmacoscintigraphic Study in The Beagle Dog. Eur J Pharm Biopharm 2007;67:515-23.

6. Lin S, Kawashima Y. Current Status and Approaches to Developing Press-Coated Chrono delivery Drug Systems. J Control Release 2012;157:331-53.

7. Singh S, Kolland M. Formulation and Evaluation of Pulsatile Drug Delivery Systems of Glipizide for the Management of Type-II Diabetes Mellitus. J Drug Deliv Ther 2016;6(1):11-8.

8. Nagar M, Singhai S, Chopra VS, Gautam N, Trivedi P. Chronotropic Systems; an Emerging Trend in Drug Delivery for Pulsed Release in Chronopharmacotherapy. Int J Pharm Clin Res 2010;2:9-19.

9. Sewlall S, Pillay V, Danckwerts P, Choonara EY, Ndesendo MK, DuToit LC, et al. A Timely Review of State-Of-TheArt Chronopharmaceuticals Synchronized with Biological Rhythms. Curr Drug Deliv 2010;7:370-88.

10. Yusuf S, Sleight P, Pogue J. Effects of an AngiotensinConverting-Enzyme Inhibitor, Ramipril, on Cardiovascular Events in High-Risk Patients. N Engl J Med 2000;342:145-53.

11. Glasser SP, Neutel JM, Gana TJ. Efficacy and Safety of a Once Daily Graded-Release Diltiazem Formulation in Essential Hypertension. Am J Hypertens 2003;16:51-8.

12. Vermula S, Katkum R. Colon-Specific Double-Compression Coated Pulsatile Tablets of Ketorolac Tromethamine: Formulation Development and Pharmacokinetics. J Drug Deliv Sci Tec 2015;29:78-83.

13. Patel MM. Colon: A Gateway for Chronotherapeutic Drug Delivery Systems. Expert Opin Drug Deliv 2015;12:1389-95.

14. Rompicharla B, Prabha KS, Tabasum MD. A Comprehensive Review of Pulsatile Drug Delivery System. Int Res J Pharm 2012;3:106-114.

15. Chen K, Wang Y, Gai X, Wang H, Li Y, Wen H. Design of 
A Time-Controlled Pulsatile Release System for Propranolol Using The Dry-Coated Method: In vitro and In vivo Evaluation. AAPS PharmSci Tech 2017;18:2683-90.

16. Prajapati B, Patei G, Solanki H. Formulation and Stastical Optimization of Time Controlled Pulsatile Release Propranolol Hydrochloride Compressed Coated Tablet. J Sci Technol 2010;4(5):9-19.

17. Rujivipat S, Bodmeier R. Modified Release from Hydroxy propyl Methyl cellulose Compression-Coated Tablets. Int $\mathrm{J}$ Pharm 2010;402:72-7.

18. Indian Pharmacopoiea, Controller of Publication, Govt. of
India, Ministry of Health and Family Welfare, New Delhi, India 2018;(3):3023-24.

19. Veerareddy P, Vermula S. Formulation, Evaluation and Pharmacokinetics of Colon Targeted Pulsatile System of Flurbiprofen. J Drug Target 2012;20(8):703-14.

20. Pal P, Singh SK, Mishra S, Pandey JP, Sen G. Gum ghatti based hydrogel: Microwave synthesis, characterization, 5- Fluorouracil encapsulation and 'in vitro' drug release evaluation. Carbohydr Polym 2019;222:114979.

21. Pal P, Pandey JP, Sen G. Sesbania gum based hydrogel for as platform for sustained drug delivery: An 'in vitro' study of 5-FU release. Int J of Biol Macromol 2018;113:1116-24. 